\title{
Molecular Detection of Mycoplasma haemofelis and 'Candidatus Mycoplasma haemominutum' Infection in Cats by Direct PCR Using Whole Blood without DNA Extraction
}

\author{
Masashi WATANABE ${ }^{1)}$, Masaharu HISASUE ${ }^{1)^{*}}$, Takehisa SOUMA ${ }^{2)}$, Shuichi OHSHIRO ${ }^{3)}$, Takatsugu YAMADA ${ }^{1)}$ and \\ Ryo TSUCHIYA ${ }^{1)}$ \\ ${ }^{1)}$ Laboratory of Internal Medicine II, School of Veterinary Medicine, Azabu University, Sagamihara City, Kanagawa 229-8501, \\ ${ }^{2)}$ Maru P LifeTech Co. Ltd., Ikeda City, Osaka 563-0011 and ${ }^{3)}$ Yanbaru Animal Hospital, Nago City, Okinawa 905-0019, Japan
}

(Received 27 November 2007/Accepted 20 May 2008)

ABSTRACT. Detection of hemotropic Mycoplasma spp. infection was attempted in cats by PCR using whole blood without DNA extraction. A total 46 of $54(85 \%)$ cats with suspected Mycoplasma spp. infection showed a positive reaction, corresponding completely with the results of standard PCR testing. The direct PCR assay was sensitive enough to detect more than $0.0061 \%$ parasitemia for ' $C$. M. haemominutum' and $0.0075 \%$ parasitemia for $M$. haemofelis. These data indicate that the direct PCR assay might be sufficient for use as a tool in clinical examinations.

KEY WORDS: blood, feline, hemoplasma.

J. Vet. Med. Sci. 70(10): 1095-1099, 2008

Mycoplasma (M.) haemofelis, 'Candidatus (C.) Mycoplasma haemominutum' and ' $C$. Mycoplasma turicensis' are minute, gram-negative, epicellular bacteria infecting the feline erythrocyte and causing hemolytic anemia, thrombocytopenia, fever and jaundice [12, 16]. Definitive diagnosis of hemotropic Mycoplasma spp. infection is made by examination of a thin Wright-Giemsa-stained blood smear, but this method is unreliable because the tiny organisms often resemble stain debris, protein precipitates and HowellJolly bodies. Furthermore, parasitemic episodes are recurrent, and so examination under a microscope sometimes cannot detect the organism in some clinical cases. Recently, some reports have indicated that molecular detection of Mycoplasma spp. infection using polymerase chain reaction (PCR) based on the 16S rRNA gene of hemotropic Mycoplasma spp. is more sensitive and specific than cytological examination $[5,7,8,15]$. Therefore, PCR analysis has come to prevail as a useful and sensitive examination in veterinary laboratories in Japan. However, the cost of examination is high, and the time needed is not short. The complicated procedure and time required for the PCR assay are suspected as being the main reasons for these problems. So, it is important that these cost and time problems will be resolved in order to extend the PCR assay further into the veterinary field. A highly capable Taq polymerase has been developed that enables more efficient amplification of DNA [4]. Furthermore, several reports have revealed that direct PCR using a template such as whole blood and feces is able to detect various gene abnormalities and infectious diseases $[3,10,11]$. It is necessary to confirm the capacity of direct PCR to detect hemotropic Mycoplasma spp. infection by

\footnotetext{
* Correspondence to: Hisasue, M., Laboratory of Internal Medicine II, School of Veterinary Medicine, Azabu University, Sagamihara, Kanagawa 229-8501, Japan.

e-mail: hisasue@azabu-u.ac.jp
}

analyzing a specific population. Both the M. haemofelis and 'C. Mycoplasma haemominutum' strains were widespread in domestic cats in Japan, but sole infection with 'Candidatus Mycoplasma turicensis' has not been confirmed [6]. Therefore, direct PCR analysis to detect $M$. haemofelis and ' $C$. Mycoplasma haemominutum', was carried out in a total of 59 blood samples derived from cats with a suspected Mycoplasma spp. infection and healthy cats, and the results were compared with the standard method described previously [15].

A total of 59 blood specimens from 54 cats with a suspected Mycoplasma spp. infection, based on clinical signs and haematological abnormalities, and 5 healthy cats were used in this study. The hemotropic Mycoplasma spp.infected cats were characterized by the presence of anemia (PCV of less than 28\%), parasitemia in a blood smear and clinical features including fever, splenomegaly, jaundice and hemoglobinuria. Peripheral blood anticoagulated with EDTA was obtained from the Veterinary Teaching Hospital of Azabu University and other veterinary clinics. Parasitemia was estimated by counting the number of parasiteinfected erythrocytes per 1,000 cells on blood films stained with Wright-Giemsa solution. Extraction of genomic DNA and PCR were performed following previously reported procedures [15]. Briefly, after addition of $500 \mu \mathrm{g}$ lysozyme (Sigma-Aldrich, MO, U.S.A.) to $150 \mu l$ of blood and incubation for $1 \mathrm{hr}$ at $37^{\circ} \mathrm{C}, 200 \mu \mathrm{g}$ proteinase $\mathrm{K}$ and $100 \mu \mathrm{l}$ of $10 \%[\mathrm{w} / \mathrm{v}]$ sodium dodecyl sulfate (SDS) solution were added; the mixture was then incubated for $10 \mathrm{~min}$ at $65^{\circ} \mathrm{C}$. Following this, $100 \mu \mathrm{l}$ of $5 \mathrm{M} \mathrm{NaCl}$ solution and $160 \mu \mathrm{l}$ of $5 \%[\mathrm{w} / \mathrm{v}]$ hexadecyltrimethylammonium bromide (SigmaAldrich) were added, and the mixture was incubated for 10 min at $65^{\circ} \mathrm{C}$. The crude DNA was then purified by phenol/ chloroform extraction and ethanol precipitation, as reported previously [13]. Standard PCR was performed with $10 \mathrm{ng}$ 
of genomic DNA, $0.4 \mu \mathrm{M}$ of each primer, 1x PCR buffer, $0.2 \mathrm{mM}$ of each dNTP, 2.5 units of AmpliTaq Gold DNA polymerase (Applied Biosystems, Foster, CA, U.S.A.) and sufficient sterile water to adjust the volume to $50 \mu \mathrm{l}$. The sense and reverse primers for $M$. haemofelis were $\mathrm{OH}-\mathrm{OK} 1$ and 00CB-r1, respectively; those for ' $C$. M. haemominutum' were CA-B2 and 00CB-r1, respectively. The primer design was the same as reported previously [15]. The sequences of the sense primers $(\mathrm{OH}-\mathrm{OK} 1$ and $\mathrm{CA}-\mathrm{B} 2)$ were 5'-ATGCCCCTCTGTGGGGGATAGCCG-3' and 5'CTGGGAAAGTAGAGCTTCGCGAGC-3', respectively, and the reverse primer (00CB-r1) sequence was 5'-ATGGTATTGCTCCATCAGACTTTCG-3'. Direct PCR for hemotropic Mycoplasma spp. using feline whole blood without DNA extraction was performed. Instead of DNA, 1 $\mu \mathrm{l}$ of whole blood was used with $0.4 \mu \mathrm{M}$ of each primer, $1 \mathrm{x}$ LA PCR buffer II $\left(\mathrm{Mg}^{2+}\right.$-free), $0.2 \mathrm{mM}$ each dNTP, $4.0 \mathrm{mM}$ $\mathrm{MgCl}_{2}$ and LA Taq DNA polymerase (Takara Bio Inc., Shiga, Japan). Standard PCR was performed using an initial denaturation step of $5 \mathrm{~min}$ at $94^{\circ} \mathrm{C}$ followed by 35 cycles of denaturation at $94^{\circ} \mathrm{C}$ for $45 \mathrm{sec}$, annealing at $58.4^{\circ} \mathrm{C}$ for 45 $\mathrm{sec}$, and extension at $72^{\circ} \mathrm{C}$ for $45 \mathrm{sec}$. Feline glyceralde- hyde-3-phosphate dehydrogenase (FG3PDH) gene (GenBank accession no. M33197) was amplified simultaneously as an internal control using the forward primer 5 '-CCTTCTTGACCTACACTACAT-3' and reverse primer 5'CCAAAGTTGTCATGGATGACC-3'. The optimized cycling conditions for the direct PCR were the same as for the PCR described above, except for annealing at $58.4^{\circ} \mathrm{C}$ for 3 min. PCR products were electrophoresed on $2 \%$ agarose gel containing $0.5 \mu \mathrm{g} / \mathrm{m} l$ ethidium bromide (Sigma-Aldrich), and formation of 273- and/or 202- and 452-bp DNA bands was considered to be a positive result for infection of M. haemofelis and/or ' $C$. M. haemominutum' and G3PDH gene amplification, respectively.

Anemia (PCV $<28 \%$ ) was seen in 38 of the 54 cats (70.4\%) with a range of PCV values between 9-44\% (mean, $20.9 \pm 9.53 \%$; Table 1). Hemotropic Mycoplasma spp.-like organisms were detected in 45 cats $(83.3 \%)$ by cytological examination of blood smears, and parasitemia ranged from $1.1 \%$ to $56 \%$. As a preliminary assay, a total of 4 polymerases, including LA Taq, Ex Taq, rTaq (Takara Bio Inc., Otsu, Shiga, Japan) and AmpliTaq Gold were applied to the direct and standard PCRs to assess the ability of DNA poly-

Table 1. Results of direct PCR assay using Mycoplasma spp. infected, non-infected (with other diseases) and healthy cat blood

\begin{tabular}{|c|c|c|c|c|c|c|c|c|c|c|c|c|c|}
\hline \multirow{2}{*}{$\begin{array}{r}\text { Case } \\
\text { No. }\end{array}$} & \multirow{2}{*}{$\begin{array}{r}\text { PCV } \\
(\%)\end{array}$} & \multirow{2}{*}{$\begin{array}{c}\text { Parasitemia } \\
(\%)\end{array}$} & \multicolumn{2}{|c|}{ M. haemofelis } & \multicolumn{2}{|c|}{ 'C. M. haemominutum' } & \multirow{2}{*}{$\begin{array}{c}\text { Case } \\
\text { No. }\end{array}$} & \multirow{2}{*}{$\begin{array}{r}\text { PCV } \\
(\%)\end{array}$} & \multirow{2}{*}{$\begin{array}{c}\text { Parasitemia } \\
(\%)\end{array}$} & \multicolumn{2}{|c|}{ M. haemofelis } & \multicolumn{2}{|c|}{ 'C. M. haemoтinutum' } \\
\hline & & & Blood & DNA & Blood & DNA & & & & Blood & DNA & Blood & DNA \\
\hline \multicolumn{7}{|c|}{ M. haemofelis-infected } & 32 & 24 & 5.3 & - & - & + & + \\
\hline 1 & 13 & 26 & + & + & - & - & 33 & 33 & 3.3 & - & - & + & + \\
\hline 2 & 14 & 47.7 & + & + & - & - & 34 & 32 & 5.5 & - & - & + & + \\
\hline 3 & 9 & 30 & + & + & - & - & 35 & 16 & 2 & - & - & + & + \\
\hline 4 & 33 & 20 & + & + & - & - & 36 & 35 & 6.1 & - & - & + & + \\
\hline 5 & 13 & 15 & + & + & - & - & 37 & 12 & 4 & - & - & + & + \\
\hline 6 & 10 & 20 & + & + & - & - & 38 & 44 & 7 & - & - & + & + \\
\hline 7 & 11 & 7 & + & + & - & - & 39 & 43 & 1.5 & - & - & + & + \\
\hline 8 & 15 & 15 & + & + & - & - & 40 & 9 & 5.5 & - & - & + & + \\
\hline 9 & 16 & 4 & + & + & - & - & \multicolumn{3}{|c|}{ Mix-infected } & & & & \\
\hline 10 & 9 & 56 & + & + & - & - & 41 & 17 & 10.8 & + & + & + & + \\
\hline 11 & 17 & 10 & + & + & - & - & 42 & 26 & 7.5 & + & + & + & + \\
\hline 12 & 24 & 17 & + & + & - & - & 43 & 16 & 9.1 & + & + & + & + \\
\hline 13 & 22 & 3 & + & + & - & - & 44 & 30 & 6 & + & + & + & + \\
\hline 14 & 28 & 13.5 & + & + & - & - & 45 & 17 & 7.5 & + & + & + & + \\
\hline 15 & 25 & 3.5 & + & + & - & - & 46 & 10 & 2 & + & + & + & + \\
\hline 16 & 31 & 5 & + & + & - & - & & & & & & & \\
\hline 17 & 33 & 9.6 & + & + & - & - & \multicolumn{5}{|c|}{ Diseased cat without Mycoplasma spp. infection** } & & \\
\hline 18 & 35 & ND* & + & + & - & - & 47 & 26 & ND & - & - & - & - \\
\hline 19 & 30 & 7.5 & + & + & - & - & 48 & 31 & ND & - & - & - & - \\
\hline 20 & 29 & 3 & + & + & - & - & 49 & 28 & ND & - & - & - & - \\
\hline 21 & 12 & 5 & + & + & - & - & 50 & 20 & ND & - & - & - & - \\
\hline 22 & 11 & 5 & + & + & - & - & 51 & 30 & ND & - & - & - & - \\
\hline \multicolumn{7}{|c|}{ 'C. M. haemominutum’-infected } & 52 & 25 & ND & - & - & - & - \\
\hline 23 & 11 & 1.2 & - & - & + & + & 53 & 30 & ND & - & - & - & - \\
\hline 24 & 11 & 12.5 & - & - & + & + & 54 & 26 & ND & - & - & - & - \\
\hline 25 & 12 & 4 & - & - & + & + & & & & & & & \\
\hline 26 & 16 & 6 & - & - & + & + & \multicolumn{2}{|c|}{ Healthy cat } & & & & & \\
\hline 27 & 14 & 10 & - & - & + & + & 55 & 38 & ND & - & - & - & - \\
\hline 28 & 19 & 2.5 & - & - & + & + & 56 & 46 & ND & - & - & - & - \\
\hline 29 & 24 & 3 & - & - & + & + & 57 & 42 & ND & - & - & - & - \\
\hline 30 & 25 & 5.9 & - & - & + & + & 58 & 39 & ND & - & - & - & - \\
\hline 31 & 26 & 1.1 & - & - & + & + & 59 & 43 & ND & - & - & - & - \\
\hline
\end{tabular}

+: Amplification positive. -: Negative when LA Taq DNA polymerase was used. * Not detected.

** With anemia, anorexia, chronic renal failure, fever, hematuria, hemolytic jaundice, lethargy and/or vomiting. 


\section{'C. M. haemominutum'-infected cat blood}

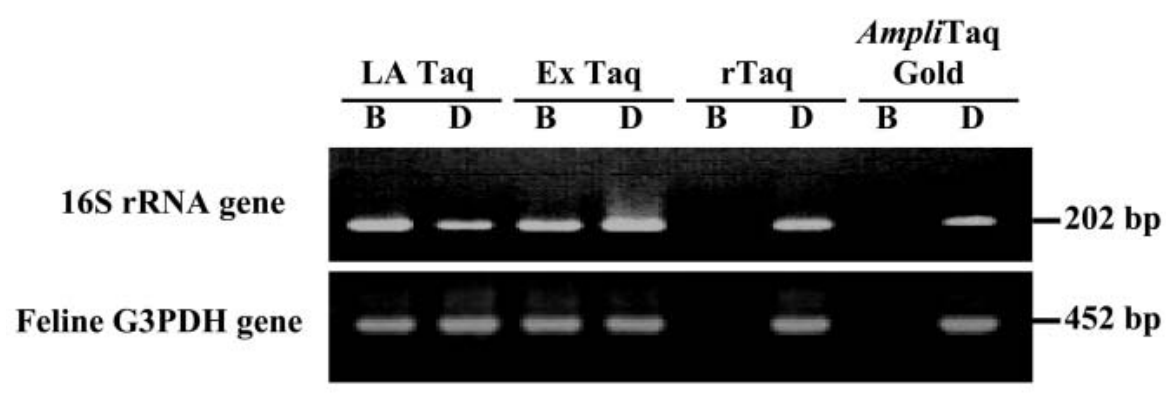

\section{M. haemofelis-infected cat}

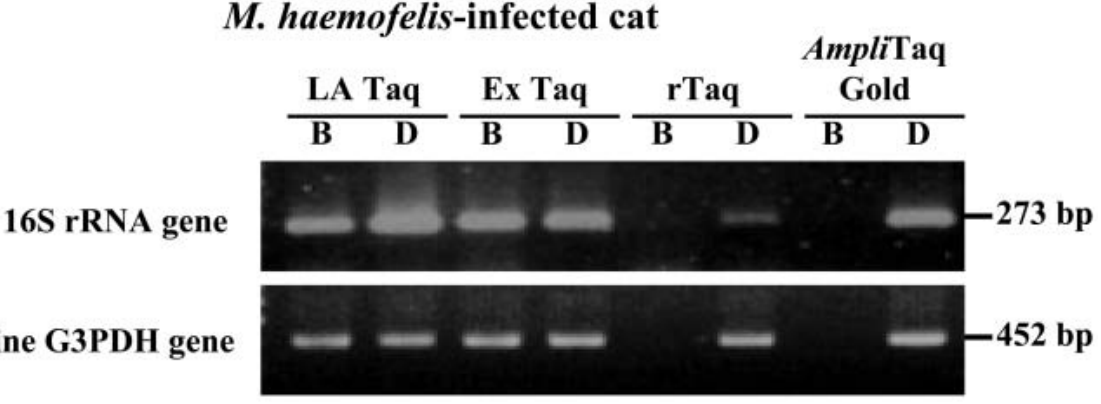

Fig. 1. 2\% agarose gel electrophoresis of the amplified DNA products from ' $C$. M. haemominutum'infected and M. haemofelis-infected cat blood (Cases 24 and 7) using various DNA polymerases, such as LA Taq, Ex Taq, rTaq and AmpliTaq Gold. B, whole blood sample; D, genomic DNA sample.

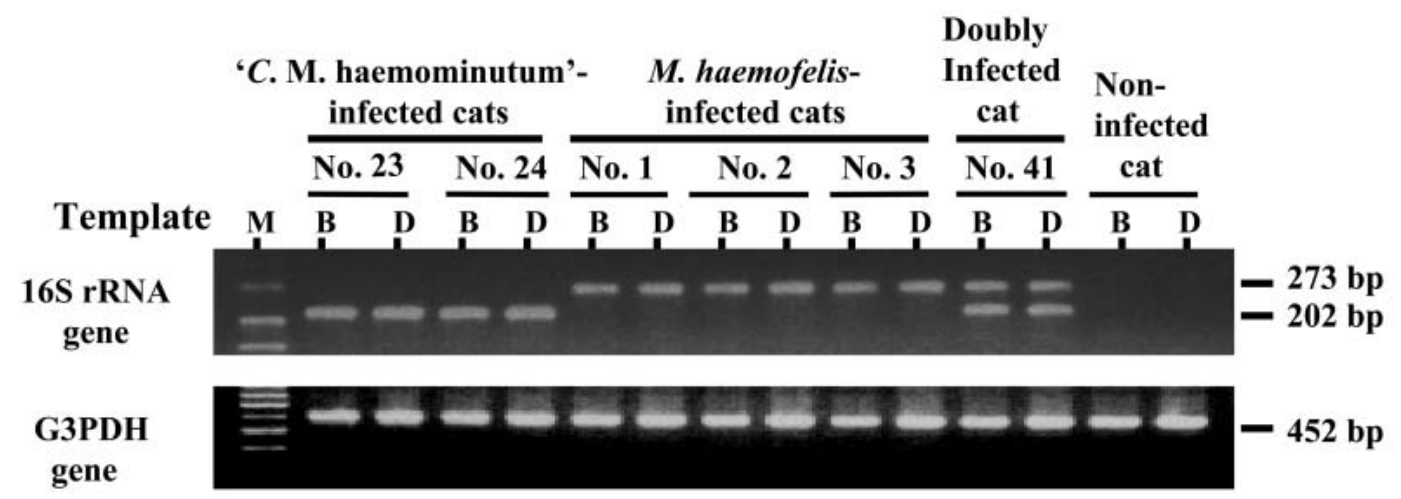

Fig. 2. Detection of parasite DNA by direct PCR using peripheral blood from cats naturally infected with M. haemofelis and ' $C$. M. haemominutum'. Analysis was performed by electrophoresis on a $2 \%$ agarose gel stained with ethidium bromide. Cases 23 and 24, infected with ' $C$. M. haemominutum', showed amplification of 202-bp DNA fragments from blood and DNA. Cases 1, 2 and 3, infected with M. haemofelis, showed amplification of a 273-bp DNA fragment. Case 41, infected with both $M$. haemofelis and ' $C$. M. haemominutum', showed simultaneous amplification with both 273-bp and 202-bp DNA fragments. An uninfected control cat did not show a distinct band. The feline G3PDH gene was amplified as the internal PCR control marker, and samples showed a distinct or thin band. M, 100 bp ladder marker; B, whole blood sample; D, genomic DNA sample.

merase in the direct PCR method. The PCR conditions were the same as the direct PCR protocol described above, and the composition of the reagents was according to the instructions for each PCR kit. The whole blood and DNA of Cases 7 and 24 were used as a template. Amplification of a 273-bp DNA fragment indicated infection with M. haemofe- lis, while amplification of a 202-bp DNA fragment indicated infection with ' $C$. M. haemominutum'. The results of PCR analysis indicated that LA Taq and Ex Taq were able to amplify DNA fragments of both 16S rRNA genes of hemotropic Mycoplasma spp. and FG3PDH from whole blood, while rTaq and AmpliTaq Gold could not amplify the 


\section{A 'C. M. haemominutum'-infected cat (Case No. 36, 6.1\% parasitemia)}

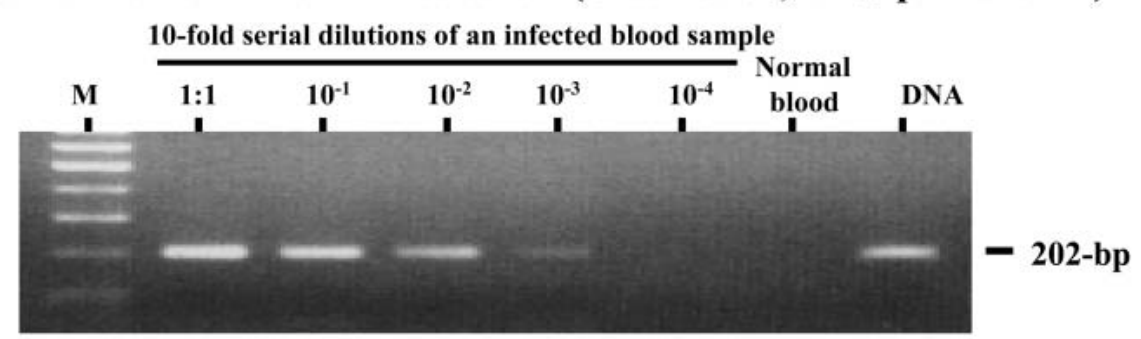

B M. haemofelis-infected cat (Case No. 19, 7.5\% parasitemia)

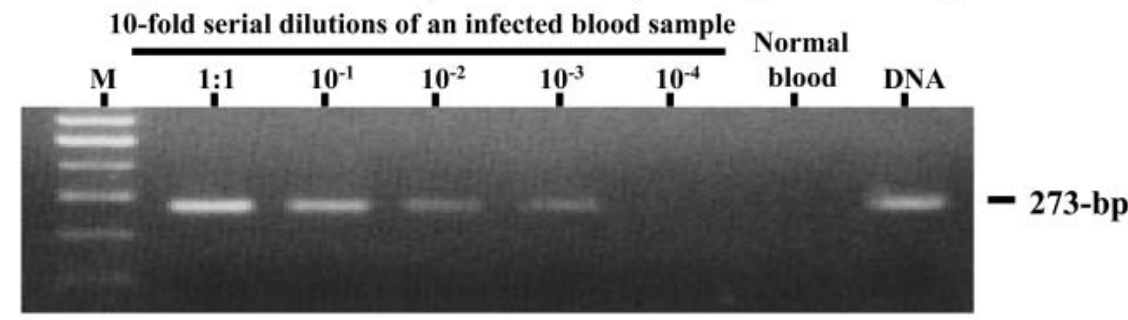

C Doubly infected cat (Case No. $42,7.5 \%$ parasitemia)

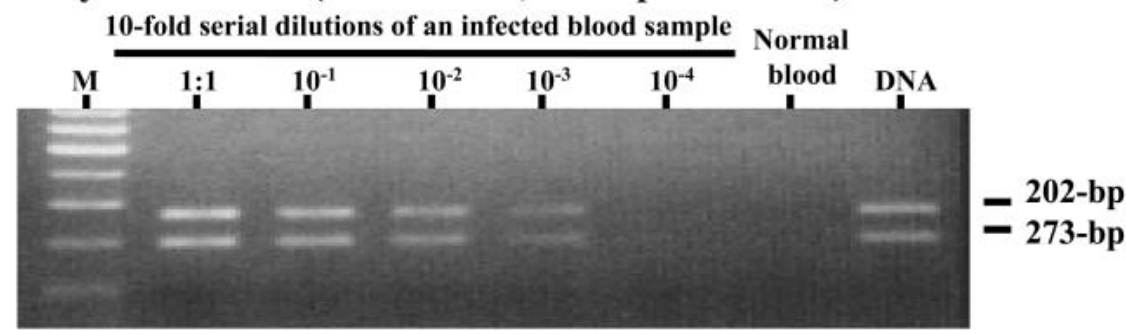

Fig. 3. Sensitivity of direct PCR for detection of parasitic infection in cat whole blood. Whole blood from cats infected with the parasites was diluted serially 10 -fold with normal cat blood, and direct PCR was performed using $1 \mu l$ of each dilution. (A) ' $C$. M. haemominutum' DNA was detected in a blood sample diluted at $10^{-3}$ (Case 36) with a parasitemia rate of $0.0061 \%$. (B) M. haemofelis DNA was detected in a blood sample diluted at $10^{-3}$ (Case 19) with a parasitemia rate of $0.0075 \%$. (C) A double infection of the above two parasites was detectable in a blood sample diluted at $10^{-3}$ (Case 42) with a parasitemia rate of $0.0075 \%$.

16S rRNA and FG3PDH genes (Fig. 1). In regard to the standard PCR, all of these polymerases were able to amplify the DNA fragments of hemotropic Mycoplasma spp. and FG3PDH. Therefore, LA Taq and Ex Taq were considered to be appropriate polymerases for amplification of DNA fragments in direct PCR. Use of whole blood in PCR reactions results in a reddish or brownish color in the final PCR products. However, this does not interfere with detection of PCR products in $2 \%$ agarose gel electrophoresis.

A total 59 blood samples were used to detect hemotropic Mycoplasma spp. by direct PCR using LA Taq and by standard PCR using AmpliTaq Gold. The electrophoretic patterns of the PCR products and results of examination are shown in Fig. 2 and Table 1, respectively. In this study, amplification of the 273-bp DNA fragment was found in 22 cats (Cases 1-22), and amplification of the 202-bp DNA fragment was found in 18 cats (Cases 23-40). In addition, both the 202-bp and 273-bp DNA fragments were amplified simultaneously in 6 cats (cases 41-46). Eight cats (cases 47-54) having other diseases, but not hemotropic Mycoplasma spp. infection, and 5 healthy cats were negative (Table 1). Thus, the DNA bands amplified by direct PCR were as visible as those of the standard method. The results of direct PCR corresponded to the standard PCR results completely. Even a blood-smear sample that was parasitemia-negative by cytological examination (case 18) was positive by direct PCR. The sequences of the PCR fragments amplified by direct PCR showed $100 \%$ homology with that for $M$. haemofelis or ' $C$. M. haemominutum' (data not shown).

To determine the sensitivity of the direct PCR assay, blood samples from Case 36 (parasitemia: 6.1\%), Case 19 (parasitemia: 7.5\%) and Case 42 (parasitemia: 7.5\%) were subjected to 10 -fold serial dilutions (from $10^{-1}$ to $10^{-4}$ ) using normal feline whole blood and were then amplified by direct PCR. Direct PCR was sensitive enough to detect parasite 
genes for ' $C$. M. haemominutum' with $0.0061 \%$ parasitemia, M. haemofelis with $0.0075 \%$ parasitemia and double infection with $0.0075 \%$ parasitemia (Fig. 3 ).

In the present study, direct PCR using whole blood without extraction of DNA detected the parasite genes with the same degree of accuracy as standard PCR methods. PCR amplification using whole blood is expected to be a suitable method for detection of blood organisms; however, peripheral blood contains various PCR-inhibitory components, such as lactoferrin, hemoglobin and heparin [1]. Two polymerases, rTaq and AmpliTaq Gold, were unable to amplify the target genes in the direct PCR. Recently, the capabilities and sensitivities of DNA polymerases have been improved; consequently, Ex Taq and LA Taq have been suggested to be capable of more efficient amplification than the usual DNA polymerase [9]. LA Taq is known to be able not only to amplify a long length genome of more than $10-\mathrm{kb}$, but also to promote specific and appropriate amplification because it prevents incorporation of base pairs. LA Taq acts to proof reading activity ( $3^{\prime} \rightarrow 5^{\prime}$ ' exonuclease activity), so it is possible that higher efficiency and fidelity may be obtained compared with normal PCR polymerase [2].

The detection limits of parasitemia in the standard PCR were estimated to be $0.00059 \%$ and $0.0002 \%$ with observation of the 202-bp (' $C$. M. haemominutum') and 273-bp ( $M$. haemofelis) DNA fragments, respectively [15]. Furthermore, in a real-time PCR system, the efficiency of amplification of ' $C$. M. haemominutum' was in the range of $10^{7}$ starting templates (corresponding to $0.0000001 \%$ parasitemia) and that of $M$. haemofelis was in the range of $10^{6}$ starting templates (corresponding to $0.000001 \%$ parasitemia) [14]. Although the direct PCR was slightly less sensitive than the standard PCR and was rather less sensitive than real-time PCR, it may be sensitive enough for practical laboratory use.

Direct PCR may reduce the time required, cost and amount of technical work; moreover, it may be useful in avoiding contamination and confusion of samples. In the present study, we demonstrated that direct PCR using whole blood is a sensitive, rapid and convenient method to make a definitive diagnosis of $M$. haemofelis and ' $C$. M. haemominutum' infections in cats.

\section{REFERENCES}

1. Al-Soud, W.A. and Radstrom, P. 2001. Purification and characterization of PCR-inhibitory components in blood cells. $J$. Clin. Microbiol. 39: 485-493.

2. Barnes, W. 1994. PCR amplification of up to $35-\mathrm{kb}$ DNA with high fidelity and high yield from $\lambda$ bacteriophage templates. Proc. Natl. Acad. Sci. 91: 2216-2220.

3. Burckhardt, J. 1994. Amplification of DNA from whole blood. PCR Methods Appli. 3: 239-243.

4. Cheng, S., Chang, S-Y. and Respess, R. 1994. Long PCR. Nature 369: 684-685.

5. Foley, J.E., Harrus, S., Poland, A., Chomel, B. and Pedersen, N. C. 1998. Molecular, clinical, and pathologic comparison of two distinct strains of Haemobartonella felis in domestic cats. Am. J. Vet. Res. 59: 1581-1588.

6. Fujihara, M., Watanabe, M., Yamada, T. and Harasawa, R. 2007. Occurrence of 'Candidatus Mycoplasma turicensis' infection in domestic cats in Japan. J. Vet. Med. Sci. 69: 10611063.

7. Inokuma, H., Taroura, S., Okuda, M., Hisasue, M., Itamoto, K., Une, S., Nakaichi, M. and Taura, Y. 2004. Molecular survey of Mycoplasma haemofelis and 'Candidatus Mycoplasma haemominutum' infection in cats in Yamaguchi and surrounding areas. J. Vet. Med. Sci. 66: 1017-1020.

8. Jensen, W.A., Lappin, M.R, Kamkar, S. and Reagan, W.J. 2001. Use of a polymerase chain reaction assay to detect and differentiate two strains of Haemobartonella felis infection in naturally infected cats. Am. J. Vet. Res. 62: 604-608.

9. Kunkel, T. A. and Soni, A. 1988. Exonucleolytic proofreading enhances the fidelity of DNA synthesis by chick embryo DNA polymerase- $\gamma$. J. Biol. Chem. 263: 4450-4459.

10. McCusker, J., Dawson, M. T., Noone, D., Gannon, F. and Smith, T. 1992. Improved method for direct PCR amplification from whole blood. Nucleic Acids Res. 20: 6747.

11. Mercier, B., Gaucher, C., Feugeas, O. and Mazurier, C. 1990. Direct PCR from whole blood, without DNA extraction. Nuclic Acids Res. 18: 5908.

12. Messick, J. B. 2004. Hemotrophic mycoplasmas (hemoplasmas): a review and new insights into pathogenic potential. Vet. Clin. Pathol. 33: 2-13.

13. Sambrook, J., Fritsch, E. F. and Maniatis, T. 1989. Molecular Cloning: A Laboratory Manual. Cold Spring Harbor Laboratory Press; E.10-E.15.

14. Tasker, S., Helps, C.R., Dav, M.J. Gruffydd-Jones, T.J. and Harbour, D.A. 2003. Use of real-time PCR to detect and quantify Mycoplasma haemofelis and 'Candidatus Mycoplasma haemominutum’ DNA. J. Clin. Microbiol. 41: 439-441.

15. Watanabe, M., Hisasue, M., Hashizaki, K., Furuichi, M., Ogata, M., Hisamatsu, S., Ogi, E., Hasegawa, M., Tsuchiya, R. and Yamada, T. 2003. Molecular detection and characterization of Haemobartonella felis in domestic cats in Japan employing sequence-specific polymerase chain reaction (SSPCR). J. Vet. Med. Sci. 65: 1111-1114.

16. Willi, B., Boretti, F. S., Cattori, V., Tasker, S., Meli, M. L., Reusch, C., Lutz, H. and Hofmann-Lehmann, R. 2005. Identification, molecular characterization, and experimental transmission of a new hemoplasma isolate from a cat with hemolytic anemia in Switzerland. J. Clin. Microbiol. 43: 2581-2585. 